\title{
Microarray-Based Detection of Antibodies against SARS-CoV-2 Proteins, Common Respiratory Viruses and Type I Interferons
}

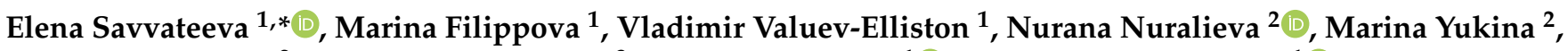 \\ Ekaterina Troshina $^{2}$, Vladimir Baklaushev ${ }^{3}$, Alexander Ivanov ${ }^{1}$ (D) and Dmitry Gryadunov ${ }^{1}$ (D) \\ 1 Center for Precision Genome Editing and Genetic Technologies for Biomedicine, Engelhardt Institute of \\ Molecular Biology, Russian Academy of Sciences, 119991 Moscow, Russia; mafilippova@mail.ru (M.F.); \\ gansfaust@mail.ru (V.V.-E.); aivanov@yandex.ru (A.I.); grad@biochip.ru (D.G.) \\ 2 Endocrinology Research Centre, Ministry of Health of Russia, 117036 Moscow, Russia; \\ nnurana@yandex.ru (N.N.); kuronova@yandex.ru (M.Y.); troshina@inbox.ru (E.T.) \\ 3 Federal Scientific and Clinical Center of Specialized Types of Medical Care and Medical Technologies of the \\ Federal Medical and Biological Agency of Russia, 115682 Moscow, Russia; serpoff@gmail.com \\ * Correspondence: len.savv@gmail.com
}

Citation: Savvateeva, E.; Filippova, M.; Valuev-Elliston, V.; Nuralieva, N.; Yukina, M.; Troshina, E.; Baklaushev, V.; Ivanov, A.; Gryadunov, D. Microarray-Based Detection of Antibodies against SARS-CoV-2 Proteins, Common Respiratory Viruses and Type I Interferons. Viruses 2021, 13, 2553. https:// doi.org/10.3390/v13122553

Academic Editors: Larisa Rudenko and Irina Isakova-Sivak

Received: 7 December 2021

Accepted: 18 December 2021

Published: 20 December 2021

Publisher's Note: MDPI stays neutral with regard to jurisdictional claims in published maps and institutional affiliations.

Copyright: (C) 2021 by the authors Licensee MDPI, Basel, Switzerland. This article is an open access article distributed under the terms and conditions of the Creative Commons Attribution (CC BY) license (https:// creativecommons.org/licenses/by/ $4.0 /)$.

\begin{abstract}
A microarray-based assay to detect IgG and IgM antibodies against betacoronaviruses (SARS-CoV-2, SARS, MERS, OC43, and HKU1), other respiratory viruses and type I interferons (IFN-Is) was developed. This multiplex assay was applied to track antibody cross-reactivity due to previous contact with similar viruses and to identify antibodies against IFN-Is as the markers for severe COVID-19. In total, 278 serum samples from convalescent plasma donors, COVID-19 patients in the intensive care unit (ICU) and patients who recovered from mild/moderate COVID-19, vaccine recipients, prepandemic and pandemic patients with autoimmune endocrine disorders, and a heterogeneous prepandemic cohort including healthy individuals and chronically ill patients were analyzed. The anti-SARS-CoV-2 microarray results agreed well with the ELISA results. Regarding ICU patients, autoantibodies against IFN-Is were detected in $10.5 \%$ of samples, and $10.5 \%$ of samples were found to simultaneously contain IgM antibodies against more than two different viruses. Cross-reactivity between IgG against the SARS-CoV-2 nucleocapsid and IgG against the OC43 and HKU1 spike proteins was observed, resulting in positive signals for the SARS-CoV-2 nucleocapsid in prepandemic samples from patients with autoimmune endocrine disorders. The presence of $\operatorname{IgG}$ against the SARS-CoV-2 nucleocapsid in the absence of IgG against the SARS-CoV-2 spike RBD should be interpreted with caution.
\end{abstract}

Keywords: SARS-CoV-2; COVID-19; antibody response; autoantibodies to interferons; cross-reactivity; coronaviruses; respiratory viruses; multiplex analysis; protein microarray

\section{Introduction}

Severe acute respiratory syndrome coronavirus 2 (SARS-CoV-2) is a new infectious agent that causes coronavirus disease 2019 (COVID-19). Humoral immune responses play critical roles in protecting individuals against SARS-CoV-2 infection, particularly through the development of antibodies. There is an urgent need to understand humoral immune responses to SARS-CoV-2 and how these responses contribute to disease severity and vaccine-induced immunity. The reasons that COVID-19 ranges from asymptomatic to severe and fatal remain unknown. Studies have shown that the factors that can affect disease severity include preexisting immunity to seasonal human coronaviruses (HCoVs) [1], coinfection with other viruses [2], and the presence of autoantibodies against type I interferons (IFNs) [3].

There are currently five known human betacoronaviruses $(\beta-\mathrm{CoVs}$; OC43, HKU1, severe acute respiratory syndrome coronavirus 1 (SARS-CoV-1), Middle East respiratory syndrome coronavirus (MERS-CoV), and SARS-CoV-2) and two human alphacoronaviruses 
(229E and NL63). The seasonal HCoVs 229E, OC43, NL63 and HKU1 may cause mild upper respiratory tract disease, and the pathogenic HCoVs SARS-CoV-1, MERS-CoV and SARS-CoV-2 are associated with severe respiratory disease. Although seasonal HCoVs are responsible for up to $15-30 \%$ of common colds in adults, there are insufficient data on the epidemiology of these four viruses worldwide [4]. Cross reactions between preexisting antibodies against proteins of common seasonal coronaviruses and those of the new SARSCoV-2 have been studied by several research groups [5-7]. However, whether crossreactive antibodies against seasonal coronaviruses protect against COVID-19 requires further study [8]. Some studies have shown that preexisting immunity to seasonal HCoVs and other respiratory viruses plays a limited role in the formation of SARS-CoV-2 humoral immune responses [9]. An association between the levels of antibodies against common cold HCoVs and the symptoms of COVID-19 has also been shown [10].

On the other hand, a confirmed COVID-19 diagnosis does not rule out coinfection with other viruses. The results of studies have shown that up to 20\% of COVID-19 patients are coinfected with another respiratory virus [11]. The viral agents most frequently identified in patients hospitalized with pneumonia are rhinovirus, influenza virus, respiratory syncytial virus (RSV), parainfluenza virus (PIV), and adenovirus (AdV) [12]. IgM antibodies can be a sign of recent infection, as they are detected in the serum only for a couple of weeks in response to an infection, followed by class switching to IgG [13].

Type I IFNs constitute the main first line of defense against viruses. Bastard et al. recently found neutralizing autoantibodies against type I IFNs (IFN- $\alpha 2$ and IFN- $\omega$ ) in 10\% of patients with life-threatening COVID-19 pneumonia [3], and another study found these antibodies in 18\% of patients with fatal COVID-19 [14].

In addition to a number of approved uniplex commercial SARS-CoV-2 immunoassays [15], a wide range of serological immunoassays have been developed for simultaneous detection of antibodies against the SARS-CoV-2 and other respiratory viruses [16-19]. The performance of these assays varies depending on format of test, choice of the antigens, and sample cohorts [20,21]. Protein and peptide microarrays are versatile tools for multiple detection of virus-specific antibodies in patient sera and for efficient identification of specific immunodominant epitopes of viral proteins [22-26]. However, the possibility of simultaneous microarray-based detection of antiviral antibodies and prognostic markers of COVID-19 severity has not been demonstrated to date. The goal of this work was to design a unified assay to assess different factors possibly affecting the course of COVID-19. We developed a protein-based microarray to evaluate antiviral and anti-IFN antibodies in the serum of COVID-19 patients. The microarray contains antigens corresponding to betacoronaviruses (SARS-CoV-2, MERS-CoV, SARS-CoV-1, HKU1, and OC43), noncoronavirus respiratory viruses (influenza A (FluA), influenza B (FluB), PIV-1, PIV-2, PIV-3, AdV, and RSV), and type I IFNs (IFN- $\omega$ and IFN- $\alpha$ ). Both IgG and IgM antibodies can be evaluated simultaneously in this test. Multiplex detection of antibodies in serum samples collected during the prepandemic and pandemic periods from different cohorts of patients and healthy donors allowed us to identify some IgG cross-reactivity between different coronaviruses and to confirm the importance of autoantibodies against type I IFNs as markers of severe COVID-19.

\section{Materials and Methods}

\subsection{Clinical Data and Serum Samples}

\subsubsection{Prepandemic Cohort}

The samples collected before May 2019 at the Endocrinology Research Centre, Ministry of Health of Russia, were included in the study as the negative control group. In total, 70 serum samples were collected from naive individuals (prepandemic negative control group): healthy persons $(\mathrm{n}=22)$ and patients with endocrine (autoimmune and nonautoimmune) pathology $(n=48)$. The prepandemic cohort included patients with the following diseases: type 2 autoimmune polyglandular syndrome (APS) ( $\mathrm{n}=13)$, type 1 APS (APS-1; $n=6)$, autoimmune diabetes mellitus $(n=7)$, Graves' disease $(n=5)$, rheumatoid arthritis 
$(n=5)$, nonautoimmune diabetes mellitus $(n=4)$, hypergonadotropic hypogonadism of autoimmune genesis $(n=2)$, primary autoimmune adrenal insufficiency $(n=2)$, nonautoimmune adrenal insufficiency $(n=1)$, primary hyperparathyroidism $(n=1)$, autoimmune thyroiditis $(\mathrm{n}=1)$, and adrenal lymphoma $(\mathrm{n}=1)$.

\subsubsection{Pandemic Cohort I-Convalescent Plasma Donors}

Convalescent plasma donor samples $(n=103)$ were obtained from the Federal Research Clinical Center FMBA of Russia (Moscow). Anti-SARS-CoV-2 spike receptor-binding domain fragment Arg319-Phe541 (RBD) IgG was measured in these samples using both the developed microarray-based multiplex assay and ELISA (SARS-CoV-2-IgG-IFA test, Xema Co., Ltd., Moscow, Russia).

\subsubsection{Pandemic Cohort II-Vaccinated Individuals and Recovered COVID-19 Patients}

To assess the specificity of the anti-SARS-CoV-2 assay, serum samples from individuals vaccinated with the Sputnik V COVID-19 vaccine (Gamaleya National Research Centre for Epidemiology and Microbiology, Moscow, Russia) and patients who recovered from mild/moderate COVID-19 were included in the study $(n=9)$. In this cohort, the time post vaccination with two doses/recovery from COVID-19 was 2-9 months.

\subsubsection{Pandemic Cohort III-Patients with APS-1}

To evaluate the detection of autoantibodies against type I IFNs using the developed assay, serum samples from APS-1 patients $(n=9)$ were included in the study. Three patients had no history of COVID-19 or vaccination; six patients had recovered from mild/moderate COVID-19 and did not receive immunosuppressive therapy. For five of the APS-1 patients, paired samples were collected (prepandemic (2019) and during the pandemic (2021)).

\subsubsection{Pandemic Cohort IV_-Intensive Care Unit (ICU) Patients}

Samples collected from patients with severe COVID-19 confirmed with RT-PCR were included in the study as the positive controls. Serum samples were collected from 86 ICU patients. The samples were obtained from the Federal Research Clinical Center FMBA of Russia (Moscow).

\subsection{Microarray Manufacturing and Multiplex Assay for Antibody Detection}

The following immobilized antigens were included in the microarray layout (Figure 1): SARS-CoV-2 (spike RBD (S-RBD)) - SARS-CoV-2 spike receptor-binding domain fragment Arg319-Phe541 (8COV1, HyTest, Turku, Finland), SARS-CoV-2 N-SARS-CoV-2 nucleocapsid (8COV3, HyTest, Finland), Flu-A—influenza A virus nucleoprotein (LS-G21636, LifeSpan BioSciences, Seattle, WA, USA), RSV—respiratory syncytial virus (8RSV79, HyTest, Finland), OC43 spike protein (DAGC131, Creative Diagnostics, New York, NY, USA), HKU1 spike protein (DAGC132, Creative Diagnostics, New York, NY, USA), IFN- $\omega-$ interferon $\omega$ (300-02J, PeproTech, Cranbury, NJ, USA); IFN- $\alpha$-2a-interferon $\alpha$-2a (11100-1, PBL Assay Science, Piscataway, NJ, USA), AdV—adenovirus (8AV13, HyTest, Finland), PIV-1 - parainfluenza virus type 1 (8P76, HyTest, Finland), PIV-2 - parainfluenza virus type 2 (8P76-2, HyTest, Finland), PIV-3-parainfluenza virus type 3 (8P76-3, HyTest, Finland), Flu-B-influenza B virus nucleoprotein (LS-G138331, LifeSpan BioSciences, Seattle, WA, USA), SARS-CoV (spike)—severe acute respiratory syndrome coronavirus spike protein (DAGC111, Creative Diagnostics, New York, NY, USA), and MERS-CoV (spike)-Middle East respiratory syndrome coronavirus spike protein (DAGH10300, Creative Diagnostics, New York, NY, USA). 


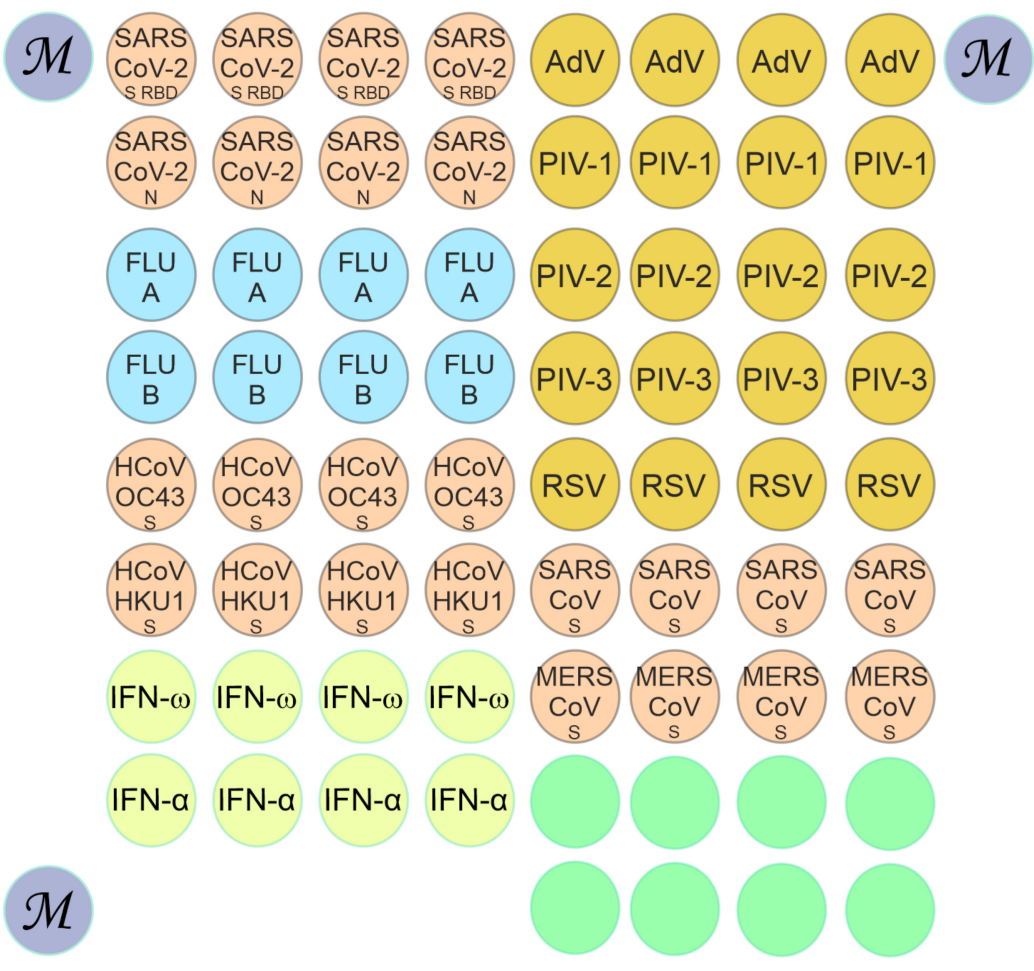

Figure 1. Configuration of the microarray for detecting antibodies against respiratory viruses and type I IFNs. Abbreviations: SARS-CoV-2 S RBD-SARS-CoV-2 spike receptor-binding domain fragment Arg319-Phe541, SARS-CoV-2 N-SARS-CoV-2 nucleocapsid, Flu A-influenza A virus nucleoprotein, Flu B-influenza B virus nucleoprotein, HCoV OC43 S-OC43 coronavirus spike protein, HCoV HKU1 S-HKU1 coronavirus spike protein, IFN- $\omega$-interferon $\omega$, IFN- $\alpha$-interferon $\alpha-2 \mathrm{a}, \mathrm{AdV}$-adenovirus, PIV-1-parainfluenza virus type 1, PIV-2-parainfluenza virus type 2, PIV-3 - parainfluenza virus type 3, RSV—respiratory syncytial virus, SARS-CoV S—severe acute respiratory syndrome coronavirus spike protein, MERS CoV S-Middle East respiratory syndrome coronavirus spike protein.

Molecular profiling of autoantibodies in serum samples was performed using hydrogelbased low-density microarrays [27]. Preparation of surfaces, mixture of gel monomers, and polymerization and blocking of microarrays were carried out as described earlier [28]. The diameter of the gel elements was $150 \pm 20 \mu \mathrm{m}$, and the distance between the elements was $300 \mu \mathrm{m}$. Each antigen was immobilized in quadruplicate elements to improve the reproducibility of the assay results (Figure 1). The microarray consists of 71 hydrogel elements: 60 elements with immobilized viral proteins and IFNs, eight elements with the gel but no immobilized proteins and three elements with a fluorescent marker (M) to allow correct positioning of the microarray when acquiring a fluorescence image after analysis.

The microarrays were probed with human sera and analyzed using a modified version of a previously published technique [28]. In brief, blood serum samples from patients were diluted 1:100 in PBS buffer with $0.14 \%$ polyvinyl alcohol $(50 \mathrm{kDa})$ and $0.14 \%$ polyvinylpyrrolidone ( $360 \mathrm{kDa}$ ) (all from Sigma-Aldrich, St. Louis, MO, USA) and applied to the microarray elements $(100 \mu \mathrm{L})$. After incubation (usually overnight, $37^{\circ} \mathrm{C}$ ), intermediate washing (PBS with 0.1\% Tween 20 (Sigma-Aldrich, St. Louis, MO, USA), 20 min), rinsing and drying, the microarrays were treated with a mixture of fluorescently labeled antibodies $\left(5 \mu \mathrm{g} / \mathrm{mL} ; \mathrm{F}\left(\mathrm{ab}^{\prime}\right)\right.$ 2-goat anti-human IgG-Cy5, and $5 \mu \mathrm{g} / \mathrm{mL}$, goat anti-IgM-Cy3; $50 \mu \mathrm{L}$ in total) in PBS buffer with $0.14 \%$ polyvinyl alcohol, $0.14 \%$ polyvinylpyrrolidone and $1 \%$ BSA (Sigma-Aldrich, St. Louis, MO, USA). After incubation (30 min, $37^{\circ} \mathrm{C}$ ), the microarrays were washed (PBS with $0.1 \%$ Tween 20, $30 \mathrm{~min}$ ), rinsed with $\mathrm{H}_{2} \mathrm{O}$, and dried. Anti-species antibodies (Invitrogen, Carlsbad, CA, USA) were preliminarily labeled 
with the N-hydroxysuccinimide esters Cy5 and Cy3 (GE Healthcare, Chicago, IL, USA) according to the manufacturer's instructions, as indicated.

\subsection{Analysis of Fluorescence and Interpretation of Results}

Fluorescence images of the microarrays were acquired using a laser-excited analyzer developed at the Engelhardt Institute of Molecular Biology (EIMB, Moscow, Russia) [29]. Measurement of microarray fluorescence was carried out using ImaGel Studio software (EIMB). For better reproducibility of each group (n) of four elements with the same antigen, the resulting $I_{n}$ signal value was calculated as the median of the four corresponding fluorescence signal values [30]. The variation coefficient of the signals within one group of elements with the same antigen, i.e., for each data point, did not exceed $15 \%$. In the group of eight elements without immobilized proteins, the resulting fluorescence signal value $\mathrm{I}_{\text {ref }}$ was calculated as the median of the eight corresponding fluorescence signal values. For anti-SARS-CoV-2 antibodies, $\mathrm{I}_{\mathrm{n}} / \mathrm{I}_{\text {ref }}$ ratios for the corresponding groups of microarray elements were obtained upon analysis with samples from 22 prepandemic individuals, and three standard deviations above these ratios were taken as the cutoff values. For all other antibodies, $\mathrm{I}_{\mathrm{n}} / \mathrm{I}_{\text {ref }}$ ratios for the corresponding groups were obtained upon analysis with buffer (PBS buffer with $0.14 \%$ polyvinyl alcohol and $0.14 \%$ polyvinylpyrrolidone; $\mathrm{n}=10$ ), and three standard deviations above these values were taken as the cutoff values. The cutoff values for selecting positive signals were $I_{n} / I_{\text {ref }} \geq 2.2$ for $I g G$ antibodies and $I_{n} / I_{\text {ref }} \geq 3.8$ for IgM antibodies. All experiments to determine cutoff values were performed in triplicate. Plots and correlation coefficients were generated with MedCalc Statistical Software version 20.008 (MedCalc Software bv, Ostend, Belgium; https: / /www.medcalc.org; accessed on 25 October 2021).

\section{Results}

\subsection{Detection of Antibodies with the Microarray-Based Assay}

To determine antibody titers in serum, a protein hydrogel microarray with immobilized target antigens was designed (Figure 1). The microarray contained antigens corresponding to respiratory viruses (SARS-CoV-2, SARS-CoV-1, MERS-CoV, OC43, HKU1; FluA and FluB; AdV; RSV; PIV-1, PIV-2, and PIV-3) and type I IFNs (IFN- $\omega$ and IFN- $\alpha-2 a$ ). Virus-specific IgG and IgM antibodies as well as autoantibodies against type I IFNs were assayed using diluted serum samples. To detect immunoglobulins bound to immobilized proteins, secondary anti-species antibodies labeled with two different fluorescent dyes ( $\mathrm{Cy} 5$ and $\mathrm{Cy} 3$ ) were used. Figure 2 shows the fluorescence profiles of the microarray as the result of testing serum samples from patients with severe COVID-19.

The concordance rate between the multiplex microarray-based assay and ELISA for the detection of IgG antibodies against the SARS-CoV-2 spike RBD was determined for 103 samples from convalescent plasma donors (pandemic cohort I). To calculate the accuracy, precision and recall, the positive and negative ELISA results were used as truepositive and true-negative results, respectively. The microarray results agreed well with the ELISA results, supporting the validity of the microarray as a serological assay in SARS-CoV2 virus research (accuracy 85.4\%, precision 1.0, recall 0.73). With the results for antibodies against any of the SARS-CoV-2 proteins detected by the microarray, the accuracy and recall increased to $95.1 \%$ and 0.91 , respectively. 

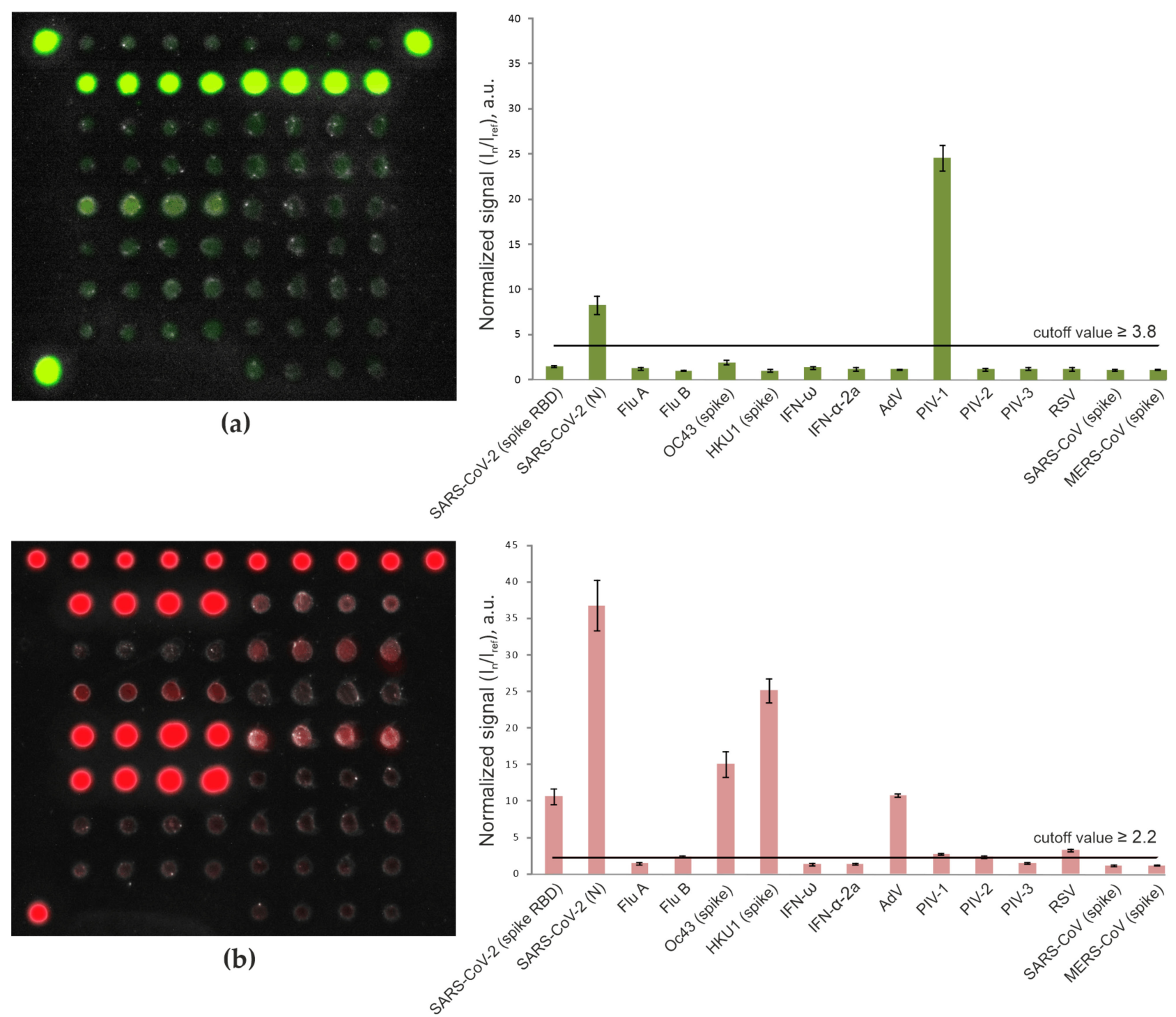

Figure 2. Fluorescence images of the microarray and values of normalized median signals $\left(\mathrm{I}_{n} / \mathrm{I}_{\text {ref }}\right)$ from the microarray elements after analysis of a serum sample from a COVID-19 ICU patient: IgM (a) and IgG (b) antibodies were detected with goat Cy3-conjugated anti-human IgM and Cy5-conjugated anti-human IgG. Error bars show the standard deviation of signals for each group of four elements with the same antigen. The cutoff values characterizing the positive signals of the microarray elements are shown by the horizontal line. Analysis of the Cy3 fluorescence profile revealed two positive signals in the groups of elements containing SARS-CoV-2 nucleocapsid and PIV-1 (a). Therefore, the tested sample was considered positive for IgM against these viruses. The Cy5 fluorescence profile was characterized by positive signals in the groups of elements containing SARS-CoV-2 spike RBD and nucleocapsid as well as those containing OC43 and HKU1 HCoV spike proteins, AdV, PIV-1 and RSV (b). Thus, the microarray detected IgG antibodies against the corresponding viruses.

\subsection{Detection of Anti-SARS-CoV-2 Antibodies in Pandemic Cohort II (Patients with Mild/Moderate COVID-19 vs. Vaccinated Individuals)}

To confirm assay specificity separately for anti-spike and anti-nucleocapsid antibodies, we included serum samples from patients who had recovered from mild/moderate COVID$19(\mathrm{n}=5)$ and individuals who had been vaccinated with the Sputnik V COVID-19 vaccine $(\mathrm{n}=4)$ in the study. All samples from the mild/moderate COVID-19 group were positive for IgG against both the SARS-CoV-2 spike and nucleocapsid, whereas samples from the vaccinated group were positive for IgG against only the SARS-CoV-2 spike RBD. None of the vaccinated patient sera demonstrated anti-SARS-CoV-2 nucleocapsid reactivity for either IgG or IgM antibodies (Figure 3). 

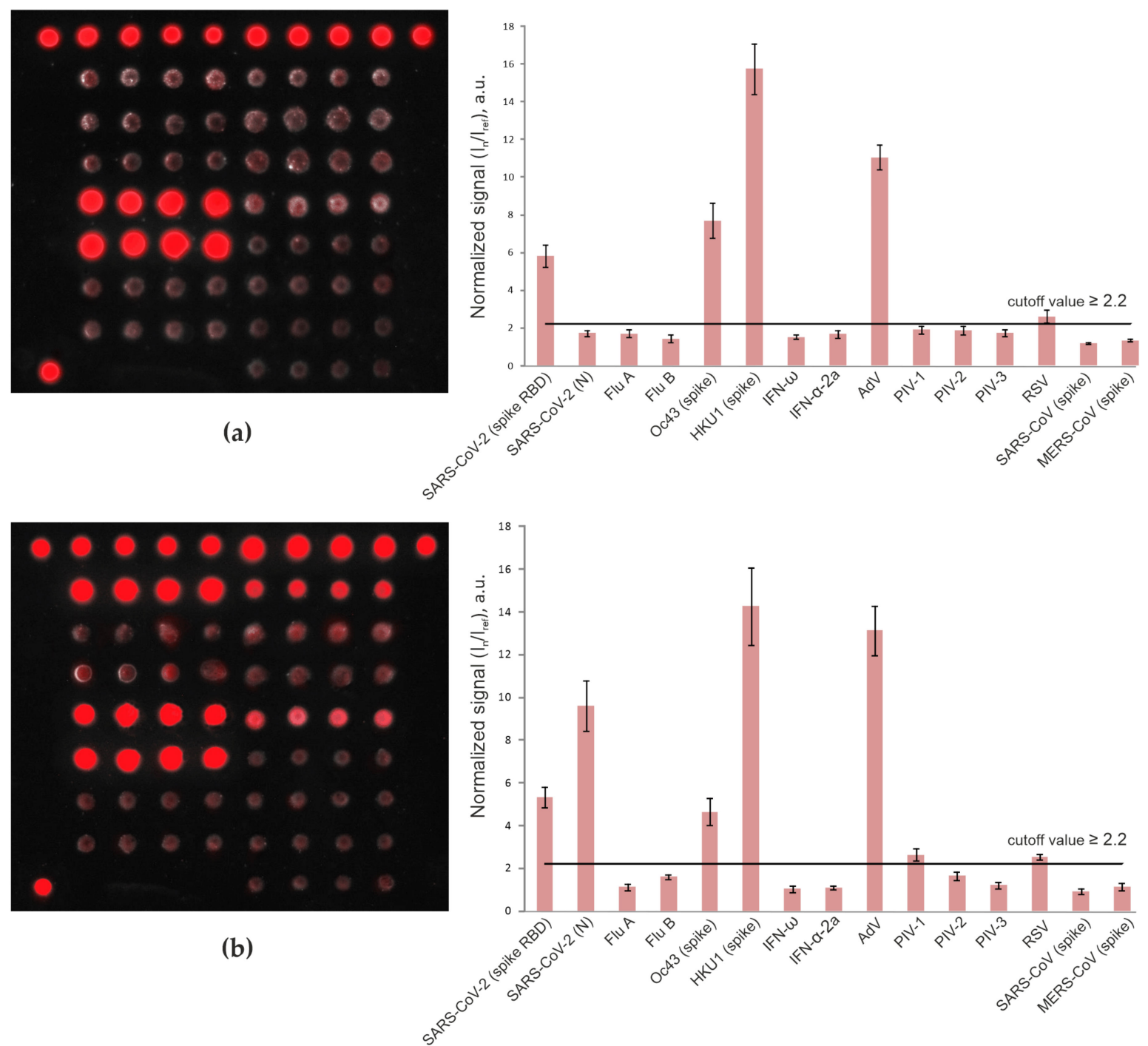

Figure 3. Fluorescence images of microarrays and values of normalized median signals $\left(\mathrm{I}_{n} / \mathrm{I}_{\text {ref }}\right)$ from the microarray elements after analysis of IgG in serum samples from a Sputnik V COVID-19 vaccine recipient (a) and a patient who had recovered from mild/moderate COVID-19 (b). Error bars show the standard deviation of signals for each group of four elements with the same antigen.

\subsection{Detection of IgG Antibodies against Betacoronaviruses}

Most prepandemic and ICU patients had IgG antibodies against the seasonal HCoVs OC43 (spike) and HKU1 (spike) due to previous infections (Supplementary Table S1). In prepandemic serum, IgG against OC43 (spike) was detected in $68.6 \%(48 / 70)$ of the samples; in COVID-19 ICU patient serum, this percentage increased to $89.5 \%$ (77/86 samples). Similarly, in prepandemic serum, IgG against HKU1 (spike) was detected in $82.9 \%$ (58/70) of the samples; in COVID-19 ICU patient serum, this proportion increased to $88.4 \%$ (76/86 samples).

Figure 4 shows the distribution of the normalized fluorescence signals $\left(I_{n} / I_{\text {ref }}\right)$ for IgG against betacoronaviruses obtained by microarray analysis in the group of COVID-19 ICU patients and in the control prepandemic cohort of healthy individuals and chronically ill tpatients. 


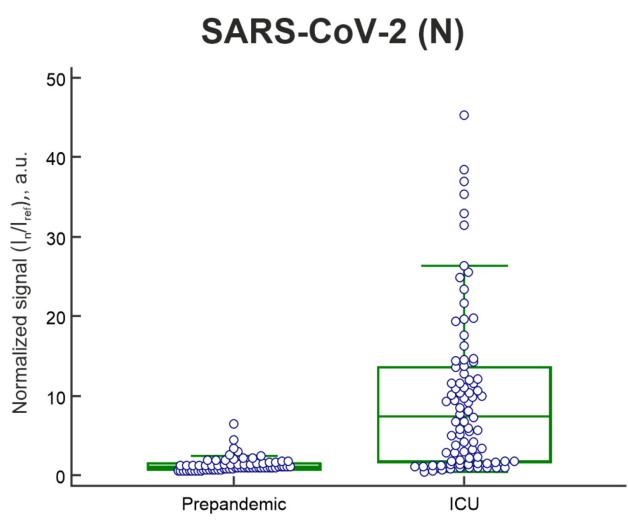

(a)

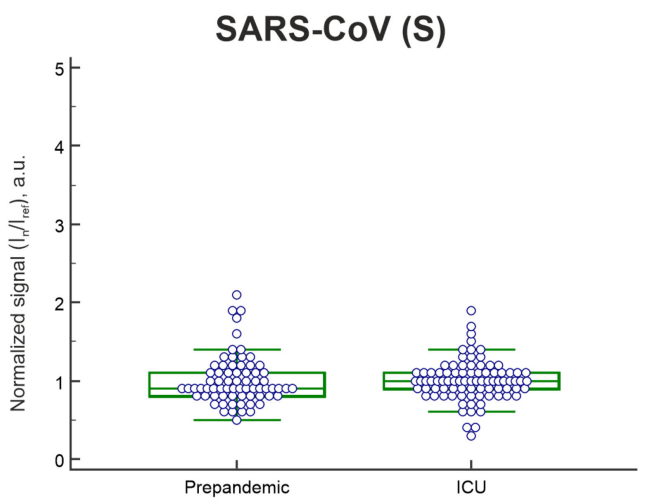

(c)

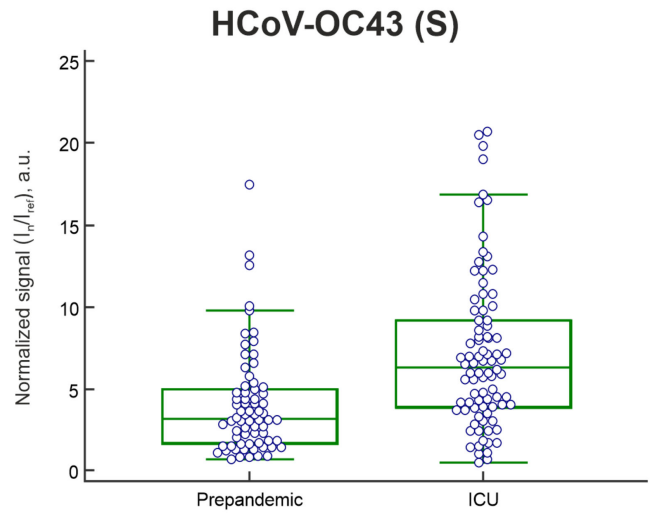

(e)

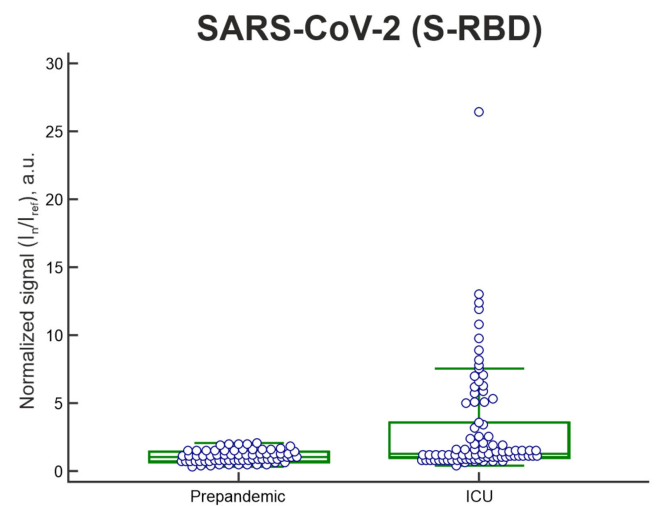

(b)

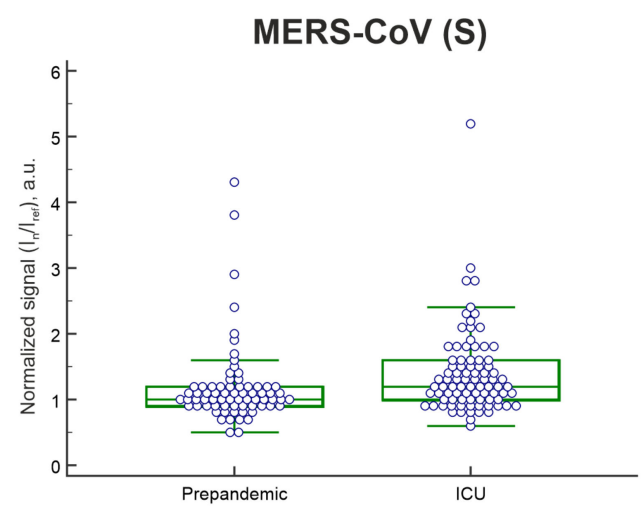

(d)

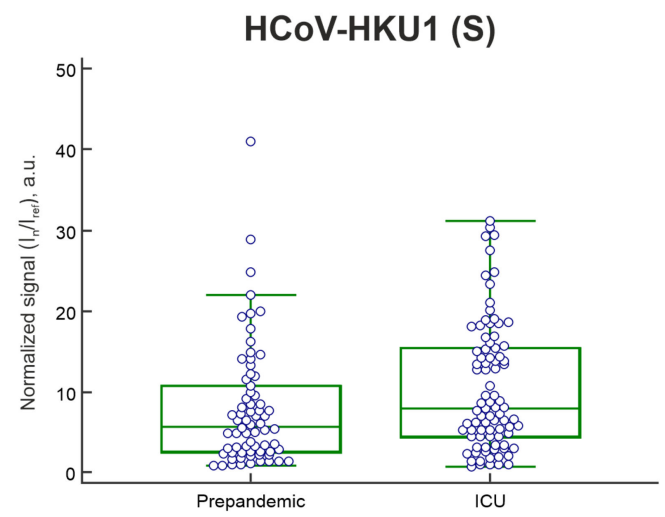

(f)

Figure 4. Humoral immune responses to betacoronaviruses in samples from the heterogeneous prepandemic cohort $(n=70)$ and samples from COVID-19 ICU patients $(n=86)$. (a) IgG against the SARS-CoV-2 nucleocapsid; (b) IgG against the SARS-CoV-2 spike RBD; (c) IgG against the SARS-CoV spike protein; (d) IgG against MERS-CoV spike protein; (e) IgG against the OC43 spike protein; (f) IgG against the HKU1 spike protein. The whisker plots show the distribution of IgG antibody titers across the prepandemic and ICU patient samples. The dots show the values of each sample. The solid black line indicates the median, and the top and bottom box boundaries indicate the first and third quartiles.

The cutoff value for antibodies against SARS-CoV-2 was determined using 22 prepandemic serum samples from healthy individuals collected before May 2019. For each antibody against SARS-CoV-2 proteins, samples with a fluorescence value greater than three standard deviations above the mean of the healthy prepandemic control samples were classified as positive. Six samples from the prepandemic cohort $(n=48)$, which 
contained patients with various pathologies, including autoimmune endocrine disorders, were considered positive for IgG against the SARS-CoV-2 nucleocapsid, and no sample was considered positive for IgG against the SARS-CoV-2 spike RBD. In these six samples, IgG against the seasonal coronaviruses OC43 (spike) and HKU1 (spike) were also detected. For three of these samples, positive signals were obtained for IgG MERS-CoV (spike). Two of the six samples were also positive for IgM against SARS-CoV-2 nucleocapsid. These antibodies were detected in the serum of patients with the following autoimmune diseases: autoimmune diabetes mellitus $(n=2)$, Graves' disease $(n=2)$, and type 2 APS $(n=2)(a u-$ toimmune diabetes mellitus + autoimmune thyroiditis, and autoimmune diabetes mellitus + autoimmune thyroiditis + Addison disease). Forty-three of the 48 prepandemic samples from patients with chronic diseases were previously characterized by ELISA and multiplex methods for positive organ-specific autoantibodies [28]. In each of the six samples positive for antibodies against the SARS-CoV-2, nucleocapsid organ-specific autoantibodies against one or more autoantigens were previously detected (Supplementary Table S2).

Correlations of the fluorescence levels for IgG antibodies against various betacoronaviruses were calculated using the values of fluorescence signals normalized to the reference signal from the empty gel elements (Table 1).

Table 1. Correlation coefficients for IgG against different betacoronaviruses in the prepandemic $(n=70)$, COVID-19 ICU $(n=86)$, and integrated prepandemic + COVID-19 ICU $(n=156)$ cohorts. The color marks cells with a significant level of correlation coefficients for IgG against different betacoronaviruses.

\begin{tabular}{|c|c|c|c|c|c|}
\hline $\begin{array}{l}\text { Prepandemic Cohort } \\
\text { SARS-2 (N) }\end{array}$ & SARS-2 (S) & SARS (S) & MERS (S) & OC43 (S) & HKU1 (S) \\
\hline SARS-2 (N) & 0.51 & 0.28 & 0.51 & 0.70 & 0.65 \\
\hline SARS-2 (S) & & 0.31 & 0.31 & 0.52 & 0.39 \\
\hline SARS (S) & & & 0.18 & 0.39 & 0.28 \\
\hline MERS (S) & & & & 0.72 & 0.36 \\
\hline OC43 (S) & & & & & 0.75 \\
\hline \multicolumn{6}{|l|}{ HKU1 (S) } \\
\hline \multicolumn{6}{|l|}{ COVID-19 ICU patients } \\
\hline SARS-2 (N) & SARS-2 (S) & SARS (S) & MERS (S) & OC43 (S) & HKU1 (S) \\
\hline SARS-2 (N) & 0.65 & 0.31 & 0.48 & 0.60 & 0.15 \\
\hline SARS-2 (S) & & 0.43 & 0.28 & 0.48 & 0.09 \\
\hline SARS (S) & & & 0.30 & 0.48 & 0.34 \\
\hline MERS (S) & & & & 0.57 & 0.24 \\
\hline OC43 (S) & & & & & 0.61 \\
\hline \multicolumn{6}{|c|}{ HKU1 (S) } \\
\hline \multicolumn{6}{|c|}{ Prepandemic cohort + COVID-19 ICU patients } \\
\hline SARS-2 (N) & SARS- 2 (S) & SARS (S) & MERS (S) & OC43 (S) & HKU1 (S) \\
\hline SARS-2 (N) & 0.70 & 0.19 & 0.41 & 0.61 & 0.21 \\
\hline SARS-2 (S) & & 0.29 & 0.27 & 0.50 & 0.14 \\
\hline SARS (S) & & & 0.24 & 0.39 & 0.30 \\
\hline MERS (S) & & & & 0.62 & 0.31 \\
\hline OC43 (S) & & & & & 0.66 \\
\hline HKU1 (S) & & & & & \\
\hline
\end{tabular}

Figure 5 shows the correlations for IgG antibodies against the various betacoronaviruses included in the microarray in the prepandemic cohort of healthy individuals and chronically ill patients. 


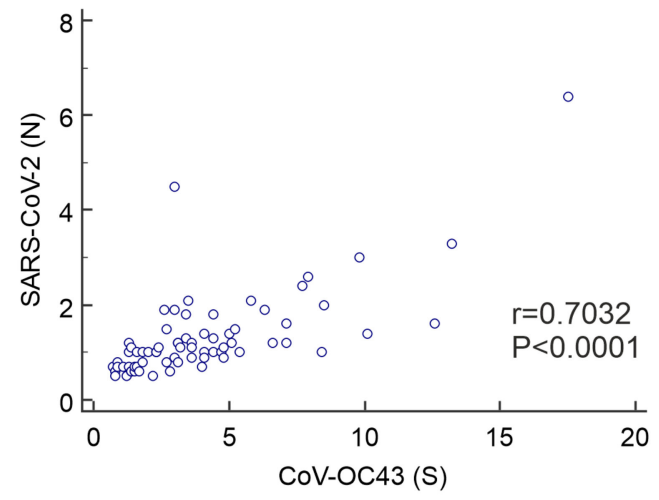

(a)

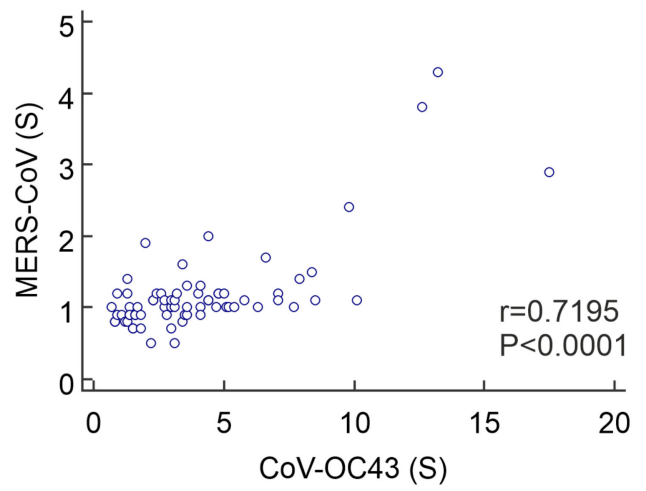

(c)

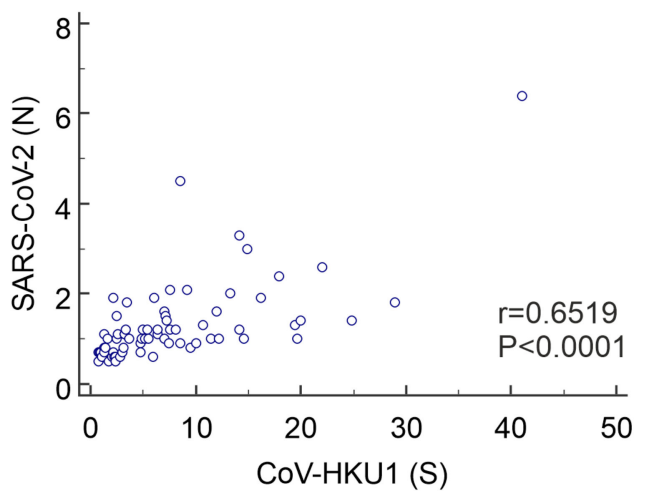

(b)

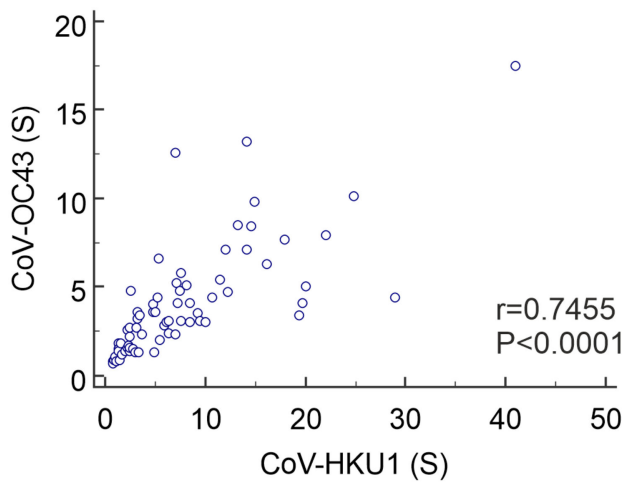

(d)

Figure 5. Scatter diagram for (a) IgG against SARS-CoV-2 (N) vs. IgG against OC43 (spike), (b) IgG against SARS-CoV-2 (N) vs. IgG against HKU1 (spike), (c) IgG against MERS-CoV (spike) vs. IgG against OC43 (spike), and (d) IgG against HKU1 (spike) vs. IgG against OC43 (spike) in the prepandemic cohort. The $\mathrm{I}_{\mathrm{n}} / \mathrm{I}_{\text {ref }}$ values are plotted along the two axes.

In the naive prepandemic cohort, fairly strong positive correlations were observed between IgG against OC43 and HKU1 $(r=0.75), \operatorname{IgG}$ against OC43 and MERS-CoV $(r=0.72)$, IgG against SARS-CoV-2 $(\mathrm{N})$ and OC43 $(\mathrm{r}=0.70)$, and IgG against SARS-CoV-2 $(\mathrm{N})$ and HKU1 $(r=0.65)$. In addition, in the cohort of COVID-19 ICU patients, positive but comparatively weak correlations remained between IgG against OC43 and HKU1 $(r=0.61)$ and IgG against SARS-CoV-2 $(\mathrm{N})$ and OC43 $(\mathrm{r}=0.60)$.

\subsection{Frequencies of Antibodies against Respiratory Viruses}

The proportions of positive IgG and IgM antibodies against all respiratory viruses included in the microarray in the prepandemic cohort and in COVID-19 ICU patients were determined using the developed assay (Figure 6). In the COVID-19 ICU patient cohort, the frequencies of antibodies against the seasonal coronaviruses OC43 and HKU1, AdV, RSV, PIV-1, and FluB were increased, and those against PIV-3 and FluA were decreased. 


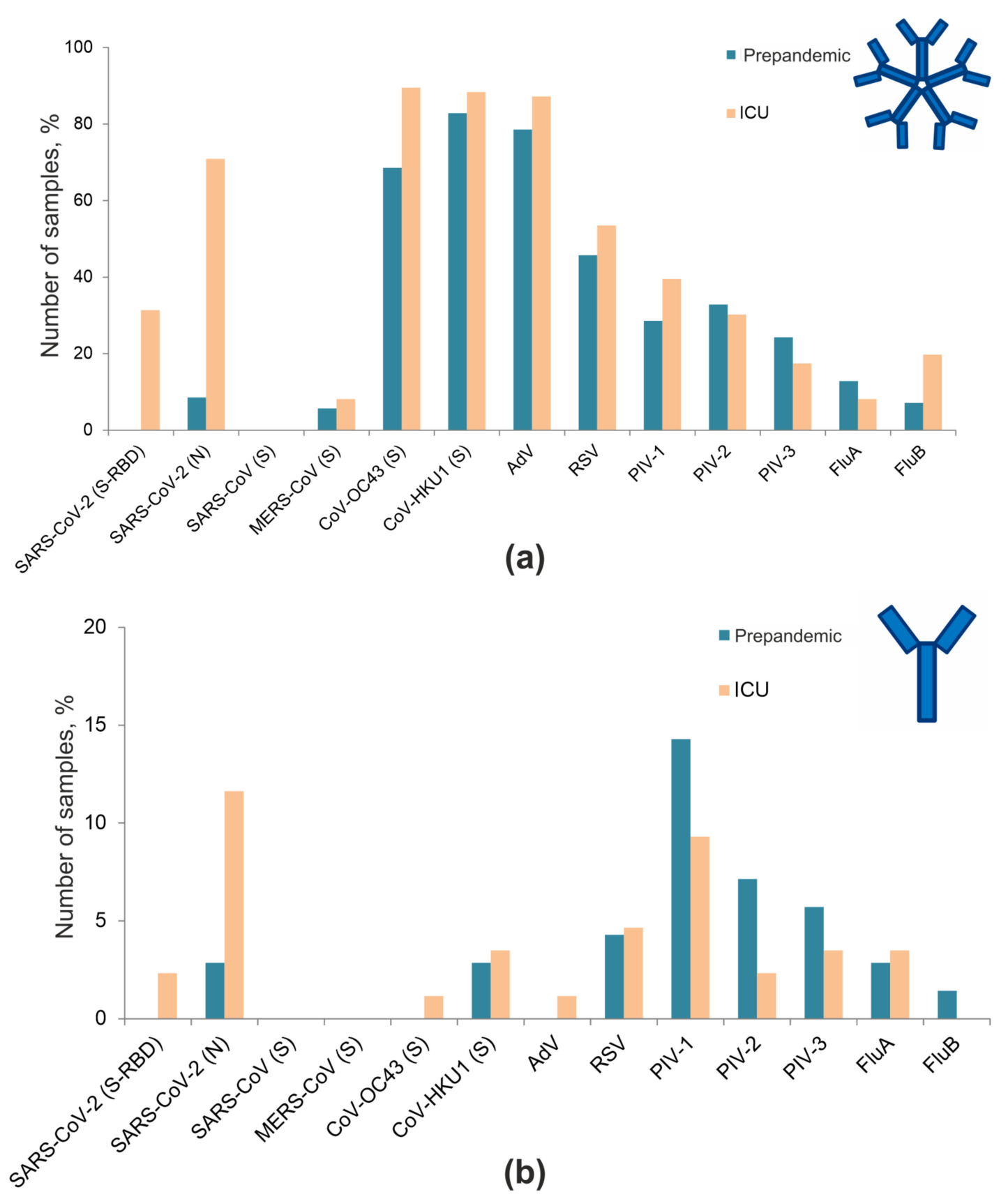

Figure 6. Frequencies of $\operatorname{IgM}(\mathbf{a})$ and $\operatorname{IgG}(\mathbf{b})$ antibodies against respiratory viruses in the prepandemic cohort and COVID-19 ICU patients.

\subsection{Detection of Autoantibodies against Type I IFNs}

APS-1 is characterized by high levels of autoantibodies (IgG) against IFN- $\omega$ and IFN- $\alpha[28,31]$. In addition, it has recently been shown that these antibodies can be markers for severe COVID-19 [3]. Figure 7 shows the distribution of IgG antibodies against type I IFNs in serum samples of APS-1 patients; in the prepandemic cohort, excluding patients with APS-1; and COVID-19 ICU patients. In 10.5\% (9/86) of COVID-19 ICU patients, autoantibodies against type I IFNs were found. However, antibodies against both IFN$\omega$ and IFN- $\alpha$ were detected in only three samples. Two serum samples contained only anti-IFN- $\omega$ antibodies, and four samples contained only anti-IFN- $\alpha$ antibodies. Moreover, only 4 of the 9 patients had anti-IFN antibody titers comparable to the high titers of these autoantibodies found in patients with APS-1. In one previously described patient with lymphoma in the prepandemic cohort $(n=64)$, both anti-IFN- $\omega$ and anti-IFN- $\alpha$ antibodies 
were detected at high titers (Patient \#56 in [28]). In two samples from healthy donors in the prepandemic cohort, anti-IFN antibodies were detected at rather low titers $\left(\mathrm{I}_{\mathrm{n}} / \mathrm{I}_{\text {ref }}\right.$ ratios of 2.5 and 3.3 , respectively).

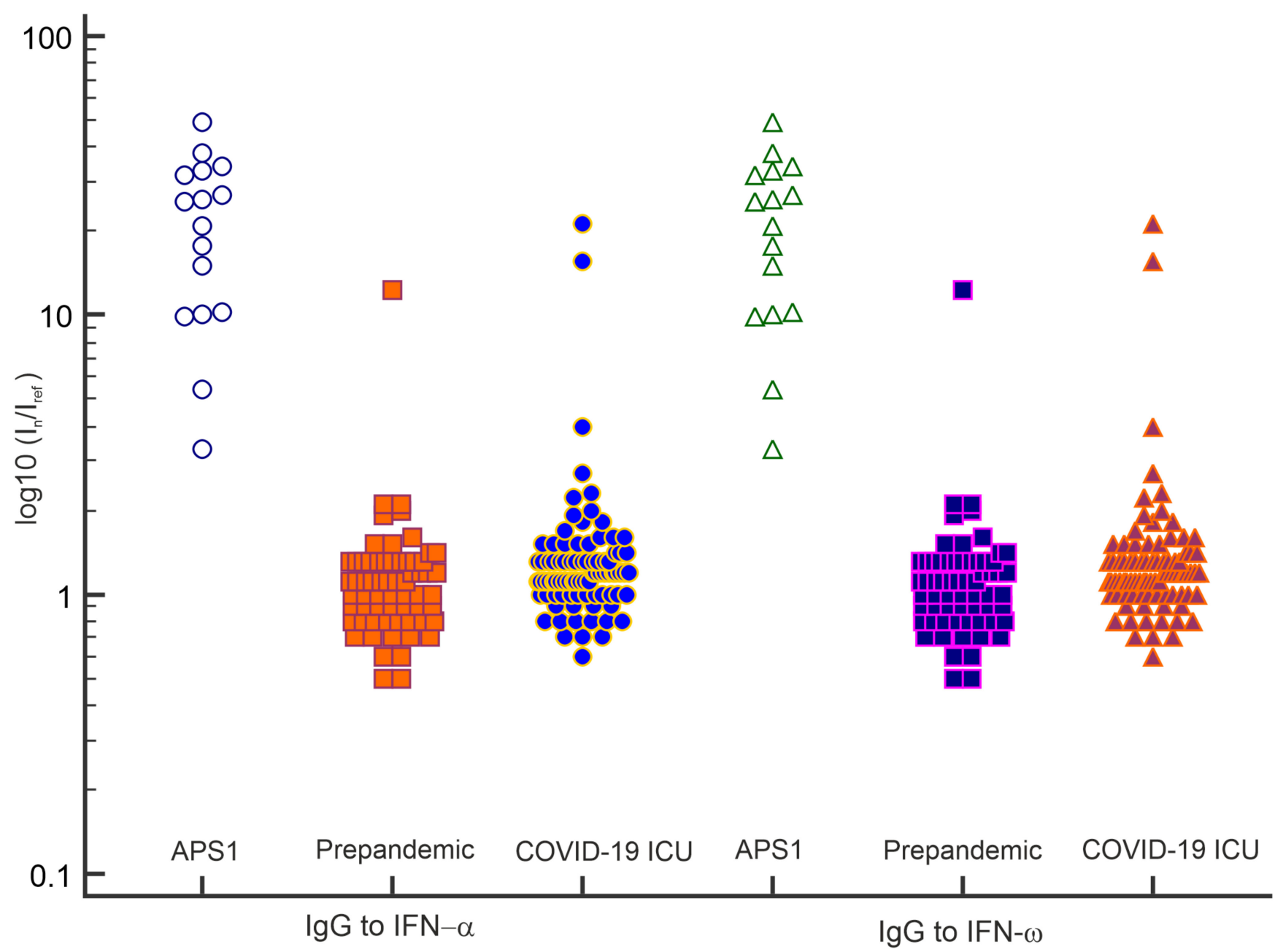

Figure 7. IgG antibodies against IFN- $\alpha$ and IFN- $\omega$ detected by the microarray assay in serum samples from APS-1 patients; the prepandemic cohort excluding APS-1 patients; and COVID-19 ICU patients. The values of the normalized fluorescence signals are log10-transformed.

A total of 16 samples from 11 APS-1 patients were included in the study. Seven samples were collected before the pandemic in 2019; nine were collected in 2021. Paired serum samples collected in 2019 and 2021 were available for five patients (Supplementary Figure S1). There were similarly high levels of IgG against IFN- $\alpha$ and IFN- $\omega$ in both the prepandemic and 2021 APS-1 patient samples. However, in the paired sera $(n=5)$, the signal level was decreased for APS-1 patients who were infected with SARS-CoV-2 $(n=4)$; this decrease was not observed in the paired sera from the one patient not exposed to SARS-CoV-2. In the assay comparing the serum samples of APS-1 patients after recovery from COVID-19 with the prepandemic samples from these patients, noticeable decreases in the signal for IgG against IFN- $\omega$ were observed: 32.8 (2019) vs. 27.0 (2021), 25.3 (2019) vs. 5.4 (2021), 48.8 (2019) vs. 31.5 (2021), and 31.1 (2019) vs. 7.1 (2021). For IgG against IFN- $\alpha$, the corresponding decreases were 50.5 (2019) vs. 37.4 (2021), 53.6 (2019) vs. 31.9 (2021), 61.1 (2019) vs. 31.7 (2021), and 45.3 (2019) vs. 27.2 (2021).

None of the prepandemic sera from APS-1 patients $(n=7)$ or pandemic sera from patients not exposed to SARS-CoV-2 $(n=3)$ showed reactivity above the cutoff value for either IgG or IgM against SARS-CoV-2 antigens. 


\section{Discussion}

Multiplex analysis of SARS-CoV-2-specific antibodies is a very attractive idea; therefore, numerous microarrays have been developed to date [17,32-34]. In this study, we describe the development of a multiplex assay based on a low-density hydrogel microarray [27]. The assay detects antibodies against SARS-CoV-2 and other respiratory viruses as well as antibodies against type I IFNs. The test can simultaneously detect IgG and IgM antibodies against human betacoronaviruses (OC43, HKU1, SARS-CoV-1, MERS-CoV, and SARS-CoV-2); RSV; AdV; PIV-1, PIV-2, and PIV-3; FluA and FluB; and type I IFNs $(\alpha$ and $\omega)$.

The developed multiplex assay was applied to track the cross-reactivity of antibodies targeting SARS-CoV-2, to detect changes in the IgG repertoire after SARS-CoV-2 infection or vaccination, to estimate the incidence of IgM antibodies against other respiratory viruses, and to estimate the percentage of patients in a cohort of patients with severe COVID-19 with autoantibodies against type I IFNs.

Differences in vaccine-induced immunity and natural infection-induced humoral immunity allowed us to demonstrate the specificity of the assay for the SARS-CoV-2 spike and nucleocapsid. Sputnik V vaccine recipients generated antibody responses to the spike protein, while patients who recovered after natural infection generated a wide range of antibodies against viral proteins, including the spike and nucleocapsid. As shown in this small sample, the microarray assay can unambiguously distinguish vaccine recipients from recovered COVID-19 patients (Figure 3).

In our study, we compared microarray results with commercial ELISA-based diagnostic kit for detection of IgG against SARS-CoV-2 spike RBD from the "Xema" company (Moscow, Russia). This test has passed all trials and was approved for in vitro diagnostic by the Federal service for surveillance in healthcare of the Russian Federation. Generally, the microarray results and the ELISA results exhibited good concordance. However, detection of IgG against the SARS-CoV-2 spike RBD was less accurate than simultaneous detection of antibodies against both the spike RBD and nucleocapsid. The decreased frequencies of spike RBD-reactive antibodies compared to nucleocapsid antibodies in the COVID-19 ICU patient cohort can be explained by several factors. First, the time elapsed since the onset of COVID-19 was unknown for the studied ICU cohort. Since IgM and IgG antibody levels change over time after infection, this parameter can be critical. Second, we used the antigenic RBD region of the SARS-CoV-2 spike protein (Arg319-Phe541 fragment). Antibody responses against the RBD have been shown to be weaker than those against the S1, S2 and N proteins; moreover, detection of the RBD by antibodies does not parallel the detection of S1 [35]. Third, the sensitivity of detection of antibodies against spike RBD differs for multiple SARS-CoV-2 variants due to changing antigenicity of the SARSCoV-2 spike protein [36]. Thus, further increases in the sensitivity and specificity of the microarray can be achieved by immobilizing not only the spike RBD and nucleocapsid but also a number of other SARS-CoV-2 proteins, including other spike subunits, membrane proteins, etc.

Most prepandemic samples as well as samples from COVID-19 ICU patients contained $\operatorname{IgG}$ against the spike protein of the OC43 and HKU1 coronaviruses. Studies have revealed that, the number of cross-reactive antibodies that recognize seasonal $\mathrm{HCoV}$ antigens is increased in patients infected with SARS-CoV-2 [37]. We showed an increase in IgG against OC43 and a less pronounced increase in IgG against HKU1 in the cohort of COVID-19 ICU patients compared with the naive prepandemic cohort.

To assess the diagnostic accuracy of the microarray in a population that had not been exposed to SARS-CoV-2, serum samples collected before May 2019 were used. Since the results of antibody assays for patients with chronic inflammatory diseases can be misleading, a heterogeneous group of patients, a naive prepandemic control group was used as a negative control. False-positive results for IgG antibodies against the SARS-CoV-2 nucleocapsid were detected in prepandemic serum samples of patients with autoimmune endocrine diseases. Six of the 48 prepandemic samples from chronically ill patients pro- 
duced false-positive results for IgG against the SARS-CoV-2 nucleocapsid. Among these patients were patients with type 1 diabetes, autoimmune thyroid diseases, and type 2 APS. None of the prepandemic samples from healthy individuals or chronically ill patients without autoimmune disorders contained antibodies against the SARS-CoV-2 nucleocapsid. Four of the prepandemic samples from chronically ill patients and seven samples from COVID-19 ICU patients also showed binding of IgG against the MERS-CoV spike, to which it is unlikely that these individuals had been exposed (Figure 4d).

Patients with autoimmune endocrine disorders are at high risk during COVID-19 outbreaks $[38,39]$. False-positive results can have detrimental effects on these patients, such as a false awareness of safety that increases the risk of infection. The complexity of the immunological changes during autoimmune disease, such as production of different autoantibodies, and formation of immune complexes, can potentially affect the specificity of SARS-CoV-2 serological assays. The aim of our study was to evaluate the specificity of SARS-Cov-2 serological microarray-based assay using not only samples from a healthy population, but also from patients with chronic inflammatory diseases. To our knowledge, this is the first study to evaluate the specificity of SARS-CoV-2 antibody tests in a group of patients with autoimmune endocrine disorders. Kharlamova et al. have recently shown a high false-positive rate when analyzing prepandemic samples of patients with chronic inflammatory diseases (multiple sclerosis, rheumatoid arthritis and systemic lupus erythematosus) using commercial serological tests [40]. Positive SARS-CoV-2 antibody test results in naive populations have previously been identified in stored prepandemic sera [13], and uninfected individuals [41]. The possible causes of false-positive detection of SARS-CoV-2 antibodies can be endogenous interfering factors, including rheumatoid factor, heterophile antibodies, human anti-animal antibodies, lysozyme, complement, and cross antigens, or exogenous interfering factors, including incomplete coagulation, specimen contamination, and insufficient optimization of the diagnostic kit's reaction system [42]. For antibodies against viruses, cross-species interactions can have an influence. Cross-reactivity of immune responses between SARS-CoV-2 and seasonal coronavirus has recently been reported $[6,43,44]$. As shown by Tso et al., the SARS-CoV-2 nucleocapsid is the major antigen recognized by these cross-reactive antibodies [45]. In our study, in the naive prepandemic cohort, cross-reactivity was observed between antibodies against the SARSCoV-2 nucleocapsid and the spike proteins of the OC43 and HKU1 seasonal coronaviruses, between antibodies against the OC43 spike and the HKU1 spike, and between antibodies against the OC43 spike and the MERS-CoV spike. However, it remains unclear whether the false-positive signals that we observed were the result of cross-reactive interactions with antibodies against other coronaviruses and whether the analysis result was influenced by endogenous factors associated with an autoimmune inflammatory process or by a combination of factors. Antibodies against the nucleocapsid of SARS-CoV-2 are an attractive diagnostic marker, as they appear earlier than antibodies against the spike protein [46]. However, considering possible cross reactions, the ideal choice for the development of an immunoassay is simultaneous assessment of both the nucleocapsid and spike proteins. Our findings on small cohorts indicate that the results of assays designed to detect antibodies against the SARS-CoV-2 nucleocapsid protein should be interpreted with caution, especially in patients with autoimmune diseases. A result of anti-SARS-CoV-2 nucleocapsid IgG-positive and anti-SARS-CoV-2 spike IgG-negative should be interpreted as truly positive for current or previous COVID-19 only at specific time points after symptom onset.

Consistent with a recent study by $\mathrm{Xu}$ et al., similar epidemiological data for the frequencies of IgG antibodies against AdV and RSV were obtained [47]. However, the expected high prevalence of IgG antibodies against the FluA and FluB nucleoproteins was not observed. Most samples were found to contain IgG against OC43 (spike) and IgG against HKU1 (spike), consistent with previously published data [48]. Moreover, IgG against OC43 (spike) and IgG against HKU1 (spike) were codetected in $78.2 \%$ of patients. IgG antibodies against three types of human PIVs (PIV-1, PIV-2 and PIV-3) were codetected in $10.9 \%$ of patients. Half of the samples (50.6\%) were found to contain IgG 
antibodies against at least one PIV. Thus, a high prevalence of IgG antibodies against respiratory viruses, which usually cause mild illness with upper respiratory symptoms in nonimmunodeficient adults, was found in the studied cohort.

As the early symptoms of COVID-19 are similar to those of other acute respiratory viral infections, a multiplex assay to detect IgM antibodies against a wide range of respiratory viruses may be helpful to reveal possible coinfections. Although IgM antibodies can be a sign of recent infection, IgM assays have limitations. First, IgM antibodies are released only at specific time points. In addition, they have lower affinity for viral antigens than IgG antibodies. Thus, the performance of IgM assays can vary and demonstrate low sensitivity, as shown in different studies [49]. In the studied cohort of COVID-19 ICU patients, IgMclass antibodies against more than two different viruses were found simultaneously in $10.5 \%$ of the samples.

Anti-type I IFN antibodies are highly specific for APS-1 patients [31]. In addition, pre-existing autoantibodies against IFN- $\alpha$ and IFN- $\omega$ can be prognostic markers for severe COVID-19 [3]. The specificity of a microarray assay for anti-type I IFN antibodies was previously confirmed for a slightly different assay [28]. In this study, the presence of autoantibodies against type I IFNs in the cohort of critically ill COVID-19 ICU patients was detected in $10.5 \%$ of the samples.

Using serum samples from APS-1 patients with known recent exposure to SARS-CoV-2, we tried to assess the changes in the levels of autoantibodies against type I IFNs in these patients compared with unexposed patients. All included APS-1 patients who contracted SARS-CoV-2 developed only mild/moderate COVID-19 symptoms and did not receive immunosuppressive therapy. Consistent with previous studies [39], similarly high levels of antibodies against type I IFNs were detected in the prepandemic (2019) and 2021 samples. However, four of the paired samples from APS-1 patients showed a notable decrease in the anti-type I IFN antibody level in the post COVID-19 recovery sample compared to the paired prepandemic sample. In contrast, the paired serum samples from the only patient with APS-1 not exposed to SARS-CoV-2 did not show the same trend. The developed method is not intended to quantify the levels of autoantibodies, and the sample size is too small to draw a conclusion. However, given the very low prevalence of APS-1 patients in the population, we can assume that this observed trend cannot be overlooked, and further research is needed. As type I IFNs are at the first line of the innate immune response to viral infection, it can be speculated that during COVID-19, some preexisting anti-type I IFN antibodies interact with their targets as the level of IFNs increases. The formation of these circulating immune complexes can lead to decreased levels of autoantibodies.

Supplementary Materials: The following are available online at https: / www.mdpi.com/article / 10.3390/v13122553/s1, Figure S1: APS-1 patients' samples collected in 2019 and 2021, Table S1: $\mathrm{I}_{\mathrm{n}} / \mathrm{I}_{\text {ref }}$ ratios obtained by microarray for all samples, Table S2: Prepandemic samples of patients with chronic diseases.

Author Contributions: E.S. designed the project, performed the experiments and wrote the manuscript; M.F. realized microarray manufacturing and performed the experiments; V.V.-E. obtained ELISA data; N.N., M.Y. and E.T. prepared serum samples for prepandemic cohort and pandemic cohort III; V.B. prepared serum samples for pandemic cohorts I and IV; A.I. prepared serum samples for pandemic cohort II, D.G. supervised the project and wrote the manuscript. All authors have read and agreed to the published version of the manuscript.

Funding: This work was supported by the Ministry of Science and Higher Education of the Russian Federation to the EIMB Center for Precision Genome Editing and Genetic Technologies for Biomedicine under the Federal Research Program for Genetic Technologies Development for 2019-27, agreement number 075-15-2019-1660. 
Institutional Review Board Statement: According to the Ethics Committees of the Endocrinology Research Centre, Ministry of Health of Russia, Moscow, Russia, Federal Research Clinical Center FMBA of Russia, Moscow, this research does not require ethical approval. All specimens used in this study were anonymous samples that omitted personal information about the patients, particularly their name or address.

Informed Consent Statement: Informed consent was obtained from all subjects involved in the study.

Data Availability Statement: The authors confirm that the data supporting the findings of this study are available within the article and/or its Supplementary Materials.

Conflicts of Interest: The authors declare no conflict of interest.

\section{References}

1. Kaplonek, P.; Wang, C.; Bartsch, Y.; Fischinger, S.; Gorman, M.J.; Bowman, K.; Kang, J.; Dayal, D.; Martin, P.; Nowak, R.P.; et al Early cross-coronavirus reactive signatures of humoral immunity against COVID-19. Sci. Immunol. 2021, 6, eabj2901. [CrossRef] [PubMed]

2. Burrel, S.; Hausfater, P.; Dres, M.; Pourcher, V.; Luyt, C.E.; Teyssou, E.; Soulié, C.; Calvez, V.; Marcelin, A.G.; Boutolleau, D. Co-infection of SARS-CoV-2 with other respiratory viruses and performance of lower respiratory tract samples for the diagnosis of COVID-19. Int. J. Infect. Dis. 2021, 102, 10-13. [CrossRef] [PubMed]

3. Bastard, P.; Rosen, L.B.; Zhang, Q.; Michailidis, E.; Hoffmann, H.-H.; Zhang, Y.; Dorgham, K.; Philippot, Q.; Rosain, J.; Béziat, V.; et al. Autoantibodies against type I IFNs in patients with life-threatening COVID-19. Science 2020, 370, 6527. [CrossRef] [PubMed]

4. Liu, D.X.; Liang, J.Q.; Fung, T.S. Human Coronavirus-229E, -OC43, -NL63, and -HKU1 (Coronaviridae). In Encyclopedia of Virology; Elsevier: Amsterdam, The Netherlands, 2021; pp. 428-440, ISBN 9780128096338.

5. Shrwani, K.; Sharma, R.; Krishnan, M.; Jones, T.; Mayora-Neto, M.; Cantoni, D.; Temperton, N.J.; Dobson, S.L.; Subramaniam, K.; McNamara, P.S.; et al. Detection of Serum Cross-Reactive Antibodies and Memory Response to SARS-CoV-2 in Prepandemic and Post-COVID-19 Convalescent Samples. J. Infect. Dis. 2021, 224, 1305-1315. [CrossRef]

6. Sealy, R.E.; Hurwitz, J.L. Cross-Reactive Immune Responses toward the Common Cold Human Coronaviruses and Severe Acute Respiratory Syndrome Coronavirus 2 (SARS-CoV-2): Mini-Review and a Murine Study. Microorganisms 2021, 9, 1643. [CrossRef]

7. Ma, Z.; Li, P.; Ji, Y.; Ikram, A.; Pan, Q. Cross-reactivity towards SARS-CoV-2: The potential role of low-pathogenic human coronaviruses. Lancet Microbe 2020, 1, e151. [CrossRef]

8. Zedan, H.T.; Nasrallah, G.K. Is preexisting immunity to seasonal coronaviruses limited to cross-reactivity with SARS-CoV-2? A seroprevalence cross-sectional study in north-eastern France. EBioMedicine 2021, 71, 103580. [CrossRef] [PubMed]

9. Loos, C.; Atyeo, C.; Fischinger, S.; Burke, J.; Slein, M.D.; Streeck, H.; Lauffenburger, D.; Ryan, E.T.; Charles, R.C.; Alter, G. Evolution of Early SARS-CoV-2 and Cross-Coronavirus Immunity. mSphere 2020, 5, e00622-20. [CrossRef]

10. Ortega, N.; Ribes, M.; Vidal, M.; Rubio, R.; Aguilar, R.; Williams, S.; Barrios, D.; Alonso, S.; Hernández-Luis, P.; Mitchell, R.A.; et al. Seven-month kinetics of SARS-CoV-2 antibodies and role of pre-existing antibodies to human coronaviruses. Nat. Commun. 2021, 12, 4740. [CrossRef] [PubMed]

11. Kim, D.; Quinn, J.; Pinsky, B.; Shah, N.H.; Brown, I. Rates of Co-infection between SARS-CoV-2 and Other Respiratory Pathogens. JAMA J. Am. Med. Assoc. 2020, 323, 2085-2086. [CrossRef] [PubMed]

12. Ruuskanen, O.; Lahti, E.; Jennings, L.C.; Murdoch, D.R. Viral pneumonia. Lancet 2011, 377, 1264-1275. [CrossRef]

13. Latiano, A.; Tavano, F.; Panza, A.; Palmieri, O.; Niro, G.A.; Andriulli, N.; Latiano, T.; Corritore, G.; Gioffreda, D.; Gentile, A.; et al False-positive results of SARS-CoV-2 IgM/IgG antibody tests in sera stored before the 2020 pandemic in Italy. Int. J. Infect. Dis. 2021, 104, 159-163. [CrossRef] [PubMed]

14. Bastard, P.; Gervais, A.; Le Voyer, T.; Rosain, J.; Philippot, Q.; Manry, J.; Michailidis, E.; Hoffmann, H.-H.; Eto, S.; Garcia-Prat, M.; et al. Autoantibodies neutralizing type I IFNs are present in $\sim 4 \%$ of uninfected individuals over 70 years old and account for $\sim 20 \%$ of COVID-19 deaths. Sci. Immunol. 2021, 6, eabl4340. [CrossRef] [PubMed]

15. Kobokovich, A.; West, R.; Gronvall, G. Serology-Based Tests for COVID19; The Johns Hopkins Center for Health: Baltimore, MD, USA, 2020.

16. Favresse, J.; Brauner, J.; Bodart, N.; Vigneron, A.; Roisin, S.; Melchionda, S.; Douxfils, J.; Ocmant, A. An original multiplex method to assess five different SARS-CoV-2 antibodies. Clin. Chem. Lab. Med. 2021, 59, 971-978. [CrossRef] [PubMed]

17. van Tol, S.; Mögling, R.; Li, W.; Godeke, G.J.; Swart, A.; Bergmans, B.; Brandenburg, A.; Kremer, K.; Murk, J.L.; van Beek, J.; et al. Accurate serology for SARS-CoV-2 and common human coronaviruses using a multiplex approach. Emerg. Microbes Infect. 2020, 9, 1965-1973. [CrossRef] [PubMed]

18. Rosado, J.; Pelleau, S.; Cockram, C.; Merkling, S.H.; Nekkab, N.; Demeret, C.; Meola, A.; Kerneis, S.; Terrier, B.; Fafi-Kremer, S.; et al. Multiplex assays for the identification of serological signatures of SARS-CoV-2 infection: An antibody-based diagnostic and machine learning study. Lancet Microbe 2021, 2, e60-e69. [CrossRef]

19. Bray, R.A.; Lee, J.H.; Brescia, P.; Kumar, D.; Nong, T.; Shih, R.; Woodle, E.S.; Maltzman, J.S.; Gebel, H.M. Development and Validation of a Multiplex, Bead-based Assay to Detect Antibodies Directed against SARS-CoV-2 Proteins. Transplantation 2021, 105, 79-89. [CrossRef] 
20. Gong, F.; Wei, H.; Li, Q.; Liu, L.; Li, B. Evaluation and Comparison of Serological Methods for COVID-19 Diagnosis. Front. Mol. Biosci. 2021, 8, 682405. [CrossRef]

21. Mohit, E.; Rostami, Z.; Vahidi, H. A comparative review of immunoassays for COVID-19 detection. Expert Rev. Clin. Immunol. 2021, 17, 573-599. [CrossRef] [PubMed]

22. Camerini, D.; Randall, A.Z.; Trappl-Kimmons, K.; Oberai, A.; Hung, C.; Edgar, J.; Shandling, A.; Huynh, V.; Teng, A.A.; Hermanson, G.; et al. Mapping SARS-CoV-2 Antibody Epitopes in COVID-19 Patients with a Multi-Coronavirus Protein Microarray. Microbiol. Spectr. 2021, 9, e01416-21. [CrossRef]

23. Sasson, J.M.; Campo, J.J.; Carpenter, R.M.; Young, M.K.; Randall, A.Z.; Trappl-Kimmons, K.; Oberai, A.; Hung, C.; Edgar, J.; Teng, A.A.; et al. Diverse Humoral Immune Responses in Younger and Older Adult COVID-19 Patients. MBio 2021, 12 , e0122921. [CrossRef]

24. Du, P.X.; Chou, Y.Y.; Santos, H.M.; Keskin, B.B.; Hsieh, M.H.; Ho, T.S.; Wang, J.Y.; Lin, Y.L.; Syu, G. Da Development and Application of Human Coronavirus Protein Microarray for Specificity Analysis. Anal. Chem. 2021, 93, 7690-7698. [CrossRef]

25. Holenya, P.; Lange, P.J.; Reimer, U.; Woltersdorf, W.; Panterodt, T.; Glas, M.; Wasner, M.; Eckey, M.; Drosch, M.; Hollidt, J.M.; et al. Peptide microarray-based analysis of antibody responses to SARS-CoV-2 identifies unique epitopes with potential for diagnostic test development. Eur. J. Immunol. 2021, 51, 1839-1849. [CrossRef]

26. Wolfe, M.; Webb, S.; Chushak, Y.; Krabacher, R.; Liu, Y.; Swami, N.; Harbaugh, S.; Chávez, J. A high-throughput pipeline for design and selection of peptides targeting the SARS-Cov-2 Spike protein. Sci. Rep. 2021, 11, 21768. [CrossRef] [PubMed]

27. Gryadunov, D.A.; Shaskolskiy, B.L.; Nasedkina, T.V.; Rubina, A.Y.; Zasedatelev, A.S. The EIMB Hydrogel Microarray Technology: Thirty Years Later. Acta Naturae 2018, 10, 4-18. [CrossRef] [PubMed]

28. Savvateeva, E.N.; Yukina, M.Y.; Nuralieva, N.F.; Filippova, M.A.; Gryadunov, D.A.; Troshina, E.A. Multiplex Autoantibody Detection in Patients with Autoimmune Polyglandular Syndromes. Int. J. Mol. Sci. 2021, 22, 5502. [CrossRef] [PubMed]

29. Lysov, Y.; Barsky, V.; Urasov, D.; Urasov, R.; Cherepanov, A.; Mamaev, D.; Yegorov, Y.; Chudinov, A.; Surzhikov, S.; Rubina, A.; et al. Microarray analyzer based on wide field fluorescent microscopy with laser illumination and a device for speckle suppression. Biomed. Opt. Express 2017, 8, 4798. [CrossRef]

30. Rubina, A.Y.; Filippova, M.A.; Feizkhanova, G.U.; Shepeliakovskaya, A.O.; Sidina, E.I.; Boziev, K.M.; Laman, A.G.; Brovko, F.A.; Vertiev, Y.V.; Zasedatelev, A.S.; et al. Simultaneous detection of seven staphylococcal enterotoxins: Development of hydrogel biochips for analytical and practical application. Anal. Chem. 2010, 82, 8881-8889. [CrossRef] [PubMed]

31. Meager, A.; Visvalingam, K.; Peterson, P.; Möll, K.; Murumägi, A.; Krohn, K.; Eskelin, P.; Perheentupa, J.; Husebye, E.; Kadota, Y.; et al. Anti-interferon autoantibodies in autoimmune polyendocrinopathy syndrome type 1. PLoS Med. 2006, 3, 1152-1164. [CrossRef]

32. Gillot, C.; Douxfils, J.; Cadrobbi, J.; Laffineur, K.; Dogné, J.-M.; Elsen, M.; Eucher, C.; Melchionda, S.; Modaffarri, É.; Tré-Hardy, M.; et al. An Original ELISA-Based Multiplex Method for the Simultaneous Detection of 5 SARS-CoV-2 IgG Antibodies Directed against Different Antigens. J. Clin. Med. 2020, 9, 3752. [CrossRef]

33. Brynjolfsson, S.F.; Sigurgrimsdottir, H.; Einarsdottir, E.D.; Bjornsdottir, G.A.; Armannsdottir, B.; Baldvinsdottir, G.E.; Bjarnason, A.; Gudlaugsson, O.; Gudmundsson, S.; Sigurdardottir, S.T.; et al. Detailed Multiplex Analysis of SARS-CoV-2 Specific Antibodies in COVID-19 Disease. Front. Immunol. 2021, 12, 695230. [CrossRef] [PubMed]

34. de Assis, R.R.; Jain, A.; Nakajima, R.; Jasinskas, A.; Felgner, J.; Obiero, J.M.; Norris, P.J.; Stone, M.; Simmons, G.; Bagri, A.; et al. Analysis of SARS-CoV-2 antibodies in COVID-19 convalescent blood using a coronavirus antigen microarray. Nat. Commun. 2021, 12, 6. [CrossRef]

35. Shah, J.; Liu, S.; Potula, H.; Bhargava, P.; Cruz, I.; Force, D.; Bazerbashi, A.; Ramasamy, R. IgG and IgM antibody formation to spike and nucleocapsid proteins in COVID-19 characterized by multiplex immunoblot assays. BMC Infect. Dis. 2021, 21, 325. [CrossRef] [PubMed]

36. Harvey, W.T.; Carabelli, A.M.; Jackson, B.; Gupta, R.K.; Thomson, E.C.; Harrison, E.M.; Ludden, C.; Reeve, R.; Rambaut, A.; Peacock, S.J.; et al. SARS-CoV-2 variants, spike mutations and immune escape. Nat. Rev. Microbiol. 2021, 19, 409-424. [CrossRef] [PubMed]

37. Woudenberg, T.; Pelleau, S.; Anna, F.; Attia, M.; Donnadieu, F.; Gravet, A.; Lohmann, C.; Seraphin, H.; Guiheneuf, R.; Delamare, C.; et al. Humoral immunity to SARS-CoV-2 and seasonal coronaviruses in children and adults in north-eastern France. EBioMedicine 2021, 70, 103495. [CrossRef]

38. Rawshani, A.; Kjölhede, E.A.; Rawshani, A.; Sattar, N.; Eeg-Olofsson, K.; Adiels, M.; Ludvigsson, J.; Lindh, M.; Gisslén, M.; Hagberg, E.; et al. Severe COVID-19 in people with type 1 and type 2 diabetes in Sweden: A nationwide retrospective cohort study. Lancet Reg. Health Eur. 2021, 4, 100105. [CrossRef] [PubMed]

39. Bastard, P.; Orlova, E.; Sozaeva, L.; Lévy, R.; James, A.; Schmitt, M.M.; Ochoa, S.; Kareva, M.; Rodina, Y.; Gervais, A.; et al. Preexisting autoantibodies to type I IFNs underlie critical COVID-19 pneumonia in patients with APS-1. J. Exp. Med. 2021, 218, e20210554. [CrossRef]

40. Kharlamova, N.; Dunn, N.; Bedri, S.K.; Jerling, S.; Almgren, M.; Faustini, F.; Gunnarsson, I.; Rönnelid, J.; Pullerits, R.; Gjertsson, I.; et al. False Positive Results in SARS-CoV-2 Serological Tests for Samples From Patients With Chronic Inflammatory Diseases. Front. Immunol. 2021, 12, 1365. [CrossRef]

41. Ng, K.W.; Faulkner, N.; Cornish, G.H.; Rosa, A.; Harvey, R.; Hussain, S.; Ulferts, R.; Earl, C.; Wrobel, A.G.; Benton, D.J.; et al. Preexisting and de novo humoral immunity to SARS-CoV-2 in humans. Science 2020, 370, 1339-1343. [CrossRef] 
42. Ye, Q.; Zhang, T.; Lu, D. Potential false-positive reasons for SARS-CoV-2 antibody testing and its solution. J. Med. Virol. 2021, 93, 4242-4246. [CrossRef]

43. Hicks, J.; Klumpp-Thomas, C.; Kalish, H.; Shunmugavel, A.; Mehalko, J.; Denson, J.P.; Snead, K.R.; Drew, M.; Corbett, K.S.; Graham, B.S.; et al. Serologic Cross-Reactivity of SARS-CoV-2 with Endemic and Seasonal Betacoronaviruses. J. Clin. Immunol. 2021, 41, 906-913. [CrossRef] [PubMed]

44. Ladner, J.T.; Henson, S.N.; Boyle, A.S.; Engelbrektson, A.L.; Fink, Z.W.; Rahee, F.; D'ambrozio, J.; Schaecher, K.E.; Stone, M.; Dong, W.; et al. Epitope-resolved profiling of the SARS-CoV-2 antibody response identifies cross-reactivity with endemic human coronaviruses. Cell Rep. Med. 2021, 2, 100189. [CrossRef] [PubMed]

45. Tso, F.Y.; Lidenge, S.J.; Peña, P.B.; Clegg, A.A.; Ngowi, J.R.; Mwaiselage, J.; Ngalamika, O.; Julius, P.; West, J.T.; Wood, C. High prevalence of pre-existing serological cross-reactivity against severe acute respiratory syndrome coronavirus-2 (SARS-CoV-2) in sub-Saharan Africa. Int. J. Infect. Dis. 2021, 102, 577-583. [CrossRef]

46. Keaney, D.; Whelan, S.; Finn, K.; Lucey, B. Misdiagnosis of SARS-CoV-2: A Critical Review of the Influence of Sampling and Clinical Detection Methods. Med. Sci. 2021, 9, 36. [CrossRef] [PubMed]

47. Xu, G.J.; Kula, T.; Xu, Q.; Li, M.Z.; Vernon, S.D.; Ndung'u, T.; Ruxrungtham, K.; Sanchez, J.; Brander, C.; Chung, R.T.; et al. Comprehensive serological profiling of human populations using a synthetic human virome. Science 2015, 348, aaa0698. [CrossRef]

48. Gorse, G.J.; Patel, G.B.; Vitale, J.N.; O'Connor, T.Z. Prevalence of antibodies to four human coronaviruses is lower in nasal secretions than in serum. Clin. Vaccine Immunol. 2010, 17, 1875-1880. [CrossRef] [PubMed]

49. Al-Jighefee, H.T.; Yassine, H.M.; Al-Nesf, M.A.; Hssain, A.A.; Taleb, S.; Mohamed, A.S.; Maatoug, H.; Mohamedali, M.; Nasrallah, G.K. Evaluation of Antibody Response in Symptomatic and Asymptomatic COVID-19 Patients and Diagnostic Assessment of New IgM/IgG ELISA Kits. Pathogens 2021, 10, 161. [CrossRef] 